\title{
'Not' Again! Another Essay on the Metaphysics of Material Objects
}

\author{
MAHRAD ALMOTAHARI \\ University of Illinois at Chicago
}

"But it is a nuisance to distinguish between the two ways of negating."
-Frege, Posthumous Writings

"Essence is expressed in grammar."

-Wittgenstein, Philosophical Investigations (Remark 371)

In a highly illuminating contribution to a recent volume about metametaphysics, Karen Bennett defends a kind of epistemic "dismissivism" about the ongoing metaphysical debate between "one-thingers" and "multithingers". According to one-thingers, a material thing and its constituent matter are numerically identical; according to multi-thingers, they're distinct. According to Bennett, however, "There do not appear to be any real grounds for choosing between the competing positions [...]. We are not justified in believing either side. These are cases of underdetermination of theory by evidence" (2009, p. 35, emphasis in original).

Bennett's view encourages a degree of pessimism. If she's right, the debate between one-thingers and multi-thingers seems poorly suited to yield knowledge, or even justified beliefs, about its subject matter. And if that's right, why not disengage from it entirely? In the end, however, Bennett softens her pessimism. She concludes her discussion by acknowledging the possibility that the debate between one-thingers and multi-thingers will be resolved on the basis of global considerations. "I have not said that there are no grounds for choosing between the competing positions; I have only said that there are few grounds for choosing - and that there are no local grounds for choosing. For all I have said here, then, it remains open that there may be some broader 
theoretical grounds that can justify our choice" (p. 37). I take it that theoretical grounds are global in that they involve a more general assessment of costs and benefits, opinions about which may vary in light of background commitments. In contrast, a deductive argument in favor of, say, one-thingism - one that doesn't require an all-things-considered appraisal of theoretical advantages and disadvantages-would provide local grounds for belief.

I'm inclined to agree with many of Bennett's observations, both about the metaphysics of material objects and about the most fruitful way to carry out metametaphysical inquiry. But I think there are persuasive local grounds for choosing one-thingism. My grounds for preferring one-thingism essentially rely on several linguistic considerations about a familiar, though somewhat puzzling, use of 'not' — a use that I've elsewhere called, following Wayne Davis (2011), “irregular negation”, but which has gone by other names, as well: "locutionary negation" (Andy Rogers 2009) and "metalinguistic negation" (Laurence Horn 1985; 1989).

In the discussion to follow I want to do two things. First, I want to dispel some lingering confusions about irregular 'not' and properly demarcate the target phenomenon. This will put us in a better position to evaluate the second part of my discussion, in which I present local grounds for choosing one-thingism. My argument was originally sketched elsewhere (Almotahari 2014b), but crucial assumptions received only a cursory discussion. I return to it here in order to raise some outstanding issues and preempt a few potential worries that my earlier presentation is likely to have elicited.

\section{Preliminaries}

We can describe the unique character of irregular negation as follows.

(IRREGULAR Sentences of the form $\left\lceil\right.$ not $\left._{\text {irregular }}-S\right\rceil$ mean that uttering 'NOT') $\quad\lceil S 1$ in the present (or some salient) context is objectionable for a reason other than the falsity of the asserted content.

I want to pause and unpack this informal description before proceeding.

Examples of irregular negation are easy to think up.

(IMPLICATURE Louie C.K. isn't FUNNY; he's HILARIOUS.

DENIAL)

(FORM DENIAL) Our radar didn't detect several aircrafts; it detected several aircraft. 
The examples here display the typical form that irregular negations instantiate. They involve an initial clause, $\lceil$ not- $X 1$, which the speaker uses to perform the speech act of denial, and a follow-up clause, $\ulcorner Y\rceil$, which the speaker uses to rectify the objectionable feature of the initial clause. The two clauses are often combined with a comma, a semicolon, or an M-dash, sometimes with a 'but' and sometimes without. In the discussion that follows, I'll simply adopt Horn's convention (1989, pp. 404-405) and represent this typical form with just a semicolon, 「not- $X ; Y\rceil$, but I'll take the schema here to subsume multiple ways of concatenating the two clauses.

The examples above also display the conversational effect of irregular negation. In both cases, use of the initial clause denies the felicity of uttering the corresponding negation-free sentence. An utterance of 'Louie C.K. is funny' implicates that the strongest thing one can say about the humor of Louie C.K. is that he's merely funny; the initial clause in IMPLICATURE DENIAL targets this presumably objectionable implicature. An utterance of 'Our radar detected several aircrafts' incorporates a voiced plural morpheme; the initial clause in FORM DENIAL targets the grammatical felicity of this decision.

The examples provide intuitively satisfying (though admittedly defeasible) evidence in favor of IRREGULAR 'NOT'. But some authors are skeptical. Davis (2011), for instance, objects that IRREGULAR 'NOT' posits a lexical ambiguity for which there isn't any cross-linguistic evidence. Bart Geurts (1998) claims that conceiving of irregular 'not' as a device for voicing objections to utterances, as opposed to propositions, yields patently false predictions. Both worries deserve to be addressed. I'll take them in turn.

In light of the conventional association between sign and signification, and the astonishing number and variety of languages, one should expect that lexical ambiguities in one language would be morphologically resolved in other languages. (Or so the thought goes, anyway.) Now, since IRREGULAR 'NOT' distinguishes the significance of irregular 'not' from descriptive 'not', we should expect there to be languages that mark the distinction with the aid of different lexical items. Interestingly, Alyson Pitts (2011, p. 363) reports that Russian, Korean, and Spanish make lexical distinctions between negative

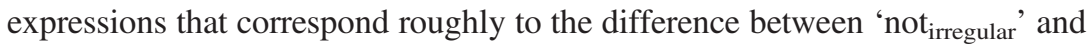

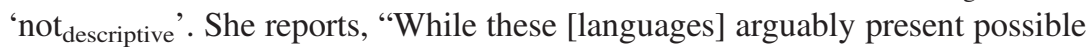
corollaries for the MN/DN distinction, in doing so, each one nevertheless appears to tease out a single thread from the bundle of features giving rise to the DN/MN distinction" (ibid.). The lexicalizations don't coincide exactly, but enough, I think, to provide some further support for IRREGULAR 'NOT'.

The objection due to Geurts is a little more involved. It can be divided into two parts. The first part relies on the assumption that if IRREGULAR 'NOT' is true, and irregular occurrences of 'not' have a metalinguistic significance, then, in a crucial respect, irregular negation is like the turnstile, ' $\vdash$ ', of formal 
logic. "Metalinguistic negation [...] applies not to propositions but to utterances [...]. Hence it would seem that metalinguistic negation has the same status as the logicians' turnstyle [sic]: ' $\vdash(\varphi \vee \neg \varphi)$ ' is not an expression of but about, say, classical logic" (Geurts 1998, pp. 282-283). In other words, the turnstile allows us to make metalinguistic claims, just as irregular negation is supposed to. On the basis of this analogy, Geurts says in the very next breath, “Therefore, Horn's characterization of metalinguistic negation leads one to expect that it cannot occur in embedded positions [...]". But the expectation is frustrated, according to Geurts, in light of examples like

(1) In America, people don't eat to[m $\alpha$ : ]toes but to[meI]toes.

Irregular 'not' occurs within the scope of a location operator in (1). So, Geurts concludes, irregular negation mustn't be a metalinguistic device.

At a first pass, it may be unclear why Geurts infers that irregular 'not' is unembeddable from the supposition that, like ' $\vdash$ ', it allows one to say something about the use of a piece of language. (It was certainly unclear to me.) But on reflection the inference is supposed to be licensed by the assumption that the metalanguage for classical logic, which ' $\vdash$ ' is part of, isn't itself part of the object language. So embedding ' $\vdash \varphi$ ' under an object language operator results in a construction that, considered from within the object language, has no interpretation. Thus, if ' not $_{\text {irregular }}$ ' is a metalinguistic device that allows one to comment on the use of a piece of language, then, according to Geurts, it too shouldn't be interpretable if embedded. I can think of no other reason why we should take the inference here to be valid. Even still, the rationale is

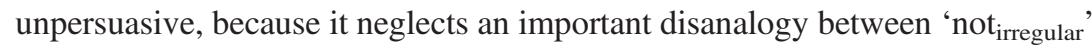

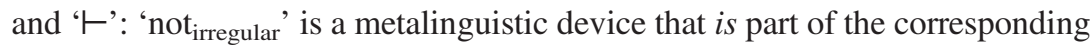
object language, namely, English. This feature of irregular negation justifies the expectation that it can be embedded under object language operators. The point here can be reinforced by analyzing (1) in the way that IRREGULAR 'NOT' recommends, treating the material that follows the use of 'but' as an elliptical rectification clause.

(2) In America, uttering 'people eat to[ma:]toes' is objectionable; people eat to[meI]toes.

In (2) we treat the negation in (1) as having metalinguistic import, but doing so yields a highly natural interpretation.

Our paradigm examples of irregular negation are IMPLICATURE DENIAL and FORM DENIAL. Some authors believe that presupposition denials, too, involve irregular negation. ${ }^{1}$

$1 \quad$ For example, see both Horn $(1985 ; 1989)$ and Geurts (1998). 
I'm now inclined to think that there are important disanalogies between our earlier examples and PRESUPPOSITION DENIAL. These disanalogies strongly suggest that something rather different is at work in presupposition denials, not irregular negation.

First, the rectification clause in an implicature or form denial provides an alternative to the problematic phrase, but the follow-up clause in presupposition denials provides an explanation of why the sentence is unacceptable, not an alternative to be used for achieving roughly the same communicative purpose. No doubt an alternative to a problematic sentence may suggest an explanation of the error it involves. In real-time exchanges, then, the distinction I'm highlighting may not matter. But, in any event, the purpose behind the one follow-up clause differs from the purpose behind the other. Ariel Cohen (2006, p. 7) makes the same point, noting that "if presupposition-based denial were the same as cases of metalinguistic negation, denying ['The king of France is bald'] would result in something like ['The KING of France isn't bald-the PRESIDENT is!'], rather than [PRESUPPOSITION DENIAL]". 2 Similarly, if presupposition denials were to be classified as irregular negations, then we should be able to produce, without infelicity, sentences like 'Louie C.K. isn't funny, because he's hilarious', but such sentences sound worse than their counterparts without 'because'.

Second, the rectification clause in an implicature or form denial is compatible with, and may even entail, the problematic sentence to which negation is applied. But this isn't true of PRESUPPOSITION DENIAL: 'The king of France is bald' and 'There is no king of France' conflict.

Third, presupposition denials fail to satisfy reliable tests for detecting irregular negation. ${ }^{3}$ Irregular negations can't be incorporated. In particular, they block negative prefixing (using 'un'-, 'im'-, 'non'-, etc.). They also prohibit the use of negative polarity items, but permit positive polarity items. Consider:

(3) \#Louie C.K. is unfunny; he's hilarious.

Chris didn't manage to solve \{\#ANY/SOME\} of the problems- he managed to solve ALL of them.

After drafting a version of this paper, I learned about Cohen's article, in which the same conclusion about presupposition denials is reached, but on the basis of a much more detailed treatment of the issues.

3 The tests are due to Horn (1989, Ch. 6). 
But, like descriptive negation generally, the use of 'not' in presupposition denials permits incorporation and standard polarity behavior. Consider:

[...] this new technology of DNA tracing has led scientists to the hypothesis that all humans descend from a single woman, who they call 'Eve'. They are busily searching for Adam - who they say is harder to find because genetic variabilities are harder to trace in the male line. It hasn't occurred to them that they are unable to find him, because he doesn't exist. ${ }^{4}$

The king of France doesn't have \{any/\#some\} hair, because there is no king of France.

More could be said to justify treating presupposition denials as descriptive negations, but I won't say it here. ${ }^{5}$ I will, however, make one observation about the negative prefixing test, since it will be highly relevant later.

Not all terms have a naturally occurring negative prefix. Consider the example immediately below.

(4) Cersei doesn't hate Tyrion; she loathes him.

In this case, the negative prefixing test can't be straightforwardly applied. What, then, lies behind our confidence in thinking that (4) involves irregular negation? Well, we know that someone who utters or accepts it is objecting to the use of 'hate' not because she believes Cersei has a pro-attitude toward Tyrion, but for some other reason. So if we ask, regarding the initial clause in (4),

(DIAGNOSTIC) Is the use of 'not', in this context, communicating the speaker's belief that the subject of her speech has a property which is incompatible with the one actually predicated?

we know the answer is no. If the use of 'not' in (4)'s initial clause were to aid in communicating such a belief, inconsistency would result, since the rectification clause expresses the belief that Cersei has an even stronger unfavorable attitude toward Tyrion than mere hatred. It's precisely

4 This example is a passage from a larger text, which can be found at http://parthenogenesis.tripod.com/Parthenogenesis2001.html. I learned of it from Ariel Cohen (2006, p. 9). The emphasis in the quotation is mine. Geurts (1998) presents his own examples of felicitous negative prefixing in presupposition denials, but draws the conclusion that the test itself is unreliable. It seems to me, however, that the test is working just fine. Despite the superficial similarity between PRESUPPOSITION DENIAL and paradigm irregular negations, the proper conclusion to draw is that the former shouldn't be classified with the latter.

5 Why should presuppositions fall outside the scope of irregular negation? This is a nice question worth thinking about. 
this sort of information-a negative answer to the DIAGNOSTIC question-that the infelicitous addition of a negative prefix is supposed to provide. A distinctive feature of the irregular use of 'not' is, after all, that it allows the speaker to avoid committing herself to the falsity of $\lceil X 1$. This explains why the primary communicative effect of sentences like (4) is perfectly coherent.

Reconsider:

(3) \#Louie C.K. is unfunny; he's hilarious.

If one took 'Louie C.K. is funny' to be objectionable because one believed that Louie was in some state incompatible with being funny, then it would be perfectly acceptable to express one's belief by using 'unfunny' (as long as one didn't follow up with, 'He's hilarious'). So, when we imagine a competent speaker uttering or accepting IMPLICATURE DENIAL we're imagining that she believes Louie C.K. is in a state compatible with being funny. The initial clause in (3) misreports that belief, since it requires a reading according to which Louie lacks the property of being funny. All of this indicates that the DIAGNOSTIC question, applied to IMPLICATURE DENIAL, yields a negative response, as one would expect. I propose that we put our DIAGNOSTIC question to use in cases where the negative prefixing test can't be straightforwardly applied, which is what I will do in the next section.

My purpose in this section was merely to say enough about what irregular negation is and how to identify its use to enable readers to evaluate my claims in the next section. Along the way I wanted to dispel some confusions that might lead certain readers to take a dim view of the argument to come. With this task completed, we're ready to move on.

\section{Local grounds for choosing one-thingism}

Why am I a one-thinger? My rationale can be quickly summarized as follows. (Refinements and qualifications will be added momentarily.)

(P1) A sentence of the form 「not- $X ; Y\rceil$ has an irregular interpretation in some context, $c$, only if, in $c$, what's asserted by a literal and sincere utterance of the initial clause on a descriptive reading of 'not', 「 not $_{\text {descriptive }}-X 1$, is incompatible with what's asserted by a literal and sincere utterance of the rectification clause, $\lceil Y\urcorner$.

(P2) An instance of ГThe piece of alloy isn't $F$, but the statue is 1 has an irregular interpretation in some context (call them, respectively, 'the relevant instance' and 'the relevant context'). 
(C1) So, in the relevant context, what's asserted by a literal and sincere utterance of the relevant instance of 「The piece of alloy is not descriptive $_{\text {. }}$ $F 7$ is incompatible with what's asserted by a literal and sincere utterance of the relevant instance of 「The statue is $F$.

(P3) If, in some context, $c$, what's asserted by a literal and sincere utterance of $\Gamma$ The $F$ is not descriptive $G\rceil$ is incompatible with what's asserted by a literal and sincere utterance of 「The $H$ is $G\rceil$, and the two asserted contents determine contingent truth-conditions, then in c $\Gamma$ The $F\rceil$ and $\Gamma$ The $H\rceil$ can be used in a literal frame of mind to pick out the same object. ${ }^{6}$

(C2) So, in the relevant context, 'The piece of alloy' and 'The statue' can be used in a literal frame of mind to pick out the same object. $^{7}$

(C3) Therefore, the piece of alloy is the statue. ${ }^{8}$

The inferences that yield (C1)-(C3) are unproblematic. (P3) is intuitively plausible, but it requires an important caveat to resist easy falsification. I postpone discussion of the caveat until later so as to avoid unnecessarily complicating things in a hurry. The truly questionable steps are, to my mind, (P1) and (P2). I'll say a few things about each premise in order to address misunderstandings and worries that have arisen in both print and personal communication. As will become clear, (P1) requires modification in one minor respect. It may be that my final statement of (P1) will also require additional bells and whistles. I'm less concerned with getting the formulation of the principle exactly right than I am with engendering confidence in something not too different from (P1) being true. An adequate

6 The qualification in terms of contingency is required to avoid certain pairs of sentences from counting as counterexamples. In particular, what's asserted by an utterance of 'The tallest male isn't male' is incompatible with what's asserted by an utterance of 'The first black President is a man', even though we might suppose that the subject terms aren't being used to pick out the same individual. However, this is due to the fact that the asserted content of 'The tallest male isn't male' is necessarily false.

7 Plausibly, both the asserted content of 'The piece of alloy is not descriptive $_{\text {Romanesque' }}$ and the asserted content of 'The statue is Romanesque' are contingent; they could have had different truth-values. This additional assumption is required to get from (P3) and (C1) to (C2).

8 I'm assuming, as seems rather obvious, that if there's a context in which $\lceil$ the $F 1$ and $\lceil$ the $G\rceil$ are used in a literal frame of mind, and in such a way as to pick out the same object, then (holding fixed that interpretation of the two descriptions) we may simply say that the $F$ is the $G$. 
refutation of (P1) would undermine such confidence, rather than take issue with the premise as I happen to state it. I hope readers keep this in mind when assessing the discussion that follows.

\subsection{Motivating (P1)}

(P1) is formulated in terms of the incompatibility of asserted contents, not in terms of the incompatibility of semantic contents. This is a rather important departure from my earlier presentation of the argument. There are two reasons for this revision.

Form denials often involve an ungrammatical initial clause. Plausibly, an ungrammatical sentence fails to semantically encode any content. Not everyone accepts such a view, of course. According to James Higginbotham (1985, p. 550), for example, "[...] nonsentences must have definite meanings, as full-blooded as those of ordinary sentences, if the source of their intuitive uninterpretablity (or merely partial interpretability) is just the violation of a rule of formal grammar". But it would be nice to formulate the argument in such a way as to cast a wide net, and to remain neutral on questions about the relation between grammaticality and meaningfulness, answers to which should be entirely sensitive to considerations internal to the science of linguistics. In any case, an even more pressing reason motivates (P1) as it's currently stated.

There's a large and ever growing literature about the semantic significance of disagreement. In recent years, contributions to the literature have been primarily concerned with evaluating the relative merits of contextualism versus relativism. Decades before this literature got going, however, H. P. Grice (1989, pp. 64-65) made an interesting observation about the phenomenon. He drew our attention to the dialogue immediately below.

(5) A: Either Wilson or Heath will be the next Prime Minister.

B: I disagree. It will be either Wilson or Thorpe.

Intuitively, A and B are disagreeing, even though the two disjunctions are logically compatible. What this shows, as authors have come to acknowledge, is that sometimes "disagreement markers can also target the result of 'factoring out' a shared assumption from the asserted content" (John MacFarlane 2014, p. 10). What's interesting for our purpose, however, is that B could have expressed her disagreement in slightly different terms. She might just as well have said,

(6) I disagree. It's not the case that either Wilson or HEATH will be the Prime Minister; it's either Wilson or THORPE. 
Notice further that infelicity would result if the negation in the initial clause of (6) were incorporated:

\#I disagree. Neither Wilson nor Heath will be Prime Minister; it's either Wilson or Thorpe.

As MacFarlane (fn. 10) observes, the intonational contour of (6), plus the inability of negation to incorporate, strongly suggests that what we have here is a case of irregular negation, and I agree. But the semantic contents of the sentences immediately below are perfectly compatible.

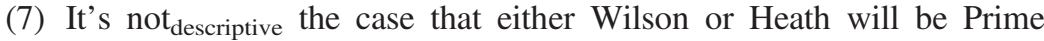
Minister.

(8) Either Wilson or Thorpe will be Prime Minister.

However, what an utterance of (7) would assert is incompatible with what an utterance of (8) would assert, though this may not be totally obvious at first.

Three points are crucial to appreciating that the asserted content of (7) is incompatible with the asserted content of (8). First, what an utterance of (7) would assert is that neither Wilson nor Heath will be Prime Minister, which entails that Wilson won't be Prime Minister. Second, if-due to ignorance, say, or a desire to be less than completely forthright — one isn't able or willing to assertively utter a sentence logically stronger than (8), as is the case in the dialogue we're imagining, then the communicative effect of asserting that either Wilson or Thorpe will be Prime Minister is equivalent to asserting that possibly Wilson will be Prime Minister and possibly Thorpe will be Prime Minister, which entails that possibly Wilson will be Prime Minister. (In case it isn't clear, 'possibly' should be assigned an epistemic interpretation in this context.) But - and this is the third point - the proposition that Wilson won't be Prime Minister, which the asserted content of (7) entails, is incompatible with the proposition that possibly Wilson will be Prime Minister, which the asserted content of (8) entails. (See Seth Yalcin (2007) for a highly illuminating discussion of "epistemic contradiction".) Thus, given MacFarlane's observation that B's response to A in (5) has an irregular interpretation, which is exemplified in (6), (P1) makes the unobvious yet demonstrably correct prediction that (7) and (8) express incompatible asserted contents. This provides some degree of abductive support in favor of the truth of (P1), not merely in favor of my present formulation.

There's another (weightier) reason to think (P1) true. Not all implicatures can be denied with the aid of irregular negation. Implicatures that are triggered by apparent violations of Quantity (Be informative!) certainly can be, 
as the examples from the previous section illustrate. But implicatures derived from apparent violations of Relation (Be relevant!) can't be. For instance, I might say 'He was able to solve the problem' in response to your question, 'Did he solve the problem?' and thereby implicate that he did solve the problem. But the relevance-based implicatum-that he did solve the problem - can't be denied as follows:

(9) \#He wasn't able to solve the problem; he didn't solve it.

The sentence is highly awkward if the initial clause is read as an attempt to selectively target and deny that he did solve the problem. Why? One would like an explanation.

(P1) is an empirical generalization about the availability of irregular negation, support for which derives from its correctly predicting the infelicity of constructions like (9). What a speaker would assert by means of

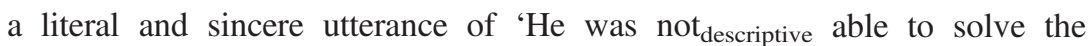
problem' is perfectly compatible with what a literal and sincere utterance of 'He didn't solve it' would convey. Given (P1), we have good reason to expect that (9) should be anomalous. Since an irregular interpretation of 'not' is unavailable, all that's left is descriptive negation, which is unsuitable for implicature denial. ${ }^{9}$

The explanation in terms of (P1) is robust across a wide range of cases. See Horn (1989, Section 6.3.2) for further discussion. See, also, Noel Burton-Roberts $(1989 \mathrm{a} ; 1989 \mathrm{~b})$, according to whom interpreters assign the use of 'not' an irregular interpretation as a way of repairing descriptive incompatibility. Horn (1989) entertains this possibility, but neither he nor I take a stand on whether the detection of incompatibility plays a role in assigning 'not' an irregular interpretation. My sole concern is with the availability of irregular interpretations, which may or may not be assigned in the way Burton-Roberts suggests. In any event, it's worth considering Robyn Carston's (1996) criticism of Burton-Roberts's proposal, since it appears to threaten (P1), as well.

Carston (p. 327) invites us to think about the example immediately below.

(10) He doesn't need FOUR MATS; he needs MORE FATS. ${ }^{10}$

9 Things are slightly more complicated, but not in a way that undermines my point. See (Almotahari 2014b, p. 396, fn. 5). I simplify for expository purposes.

10 This sentence is one of three potential counterexamples to (P1) in Carston's article. I restrict my discussion to it - ignoring the other examples - for a couple of reasons. First, discussing all three would involve a lot of repetition, since the strategy I employ in response to (10) can be straightforwardly applied to the other two examples. Second, I want to avoid making an already long and dense paper longer and denser. 
She then observes, "[This example is] obviously quite consistent when taken descriptively and I do not see any reason to suppose [it] wouldn't be interpreted as metalinguistic; that is, as [an objection] to some property of a previous utterance". Thus (10) is, potentially, a counterexample to (P1). Carston does admit, however, that a number of leading experts in linguistics disagree with her point. Even still, one would like a persuasive response, not merely an appeal to authority. The need for a convincing reply is especially urgent in this context, where so much of my argument rests on (P1).

The first observation worth making here is that the use of 'not' in (10) can receive a descriptive interpretation. Consider:

He has so many mats that he's giving them away for free. So, no, he doesn't need four mats; he needs more fats.

In this context, it's clear that the speaker takes the problematic sentence in the initial clause, 'He needs four mats', to express a falsehood, and she's objecting to the sentence for that reason. To properly assess the bearing of (10) on (P1), however, we need to consider it in a context where it would elicit an irregular interpretation.

What we're looking for is a context in which it's clear that the speaker's use of 'not' isn't voicing an objection to the truth of the asserted content expressed by the problematic sentence. What might such a context be like? Well, with respect to (10), the sort of context that comes to mind is one in which Speaker says, 'He needs /fo:r mæts/', and accidentally switches two crucial phonemes, /f/ and /m/. What Speaker really wanted to say, and would have said had she taken greater care to avoid a slip of the tongue, was 'He needs /mo:r fæts/'. Fortunately, Speaker's conversational partner, Respondent, knows which sentence Speaker intended to utter and notices both that Speaker has accidentally misplaced two phonemes and that Speaker failed to register the mistake. Respondent might then reply by uttering (10), which would strongly favor an irregular interpretation.

Since Respondent recognizes that Speaker has accidentally switched /f/ and $/ \mathrm{m} /$, Respondent knows that Speaker is intending to assert (albeit in an obscure sort of way, which is likely to impede successful communication with others) that he (the subject of her speech, whoever "he" is) needs more fats (in his diet, say). In this context, then, the asserted content of Speaker's utterance, 'He needs /fo:r mæts/', is that "he" needs more fats. Let ' $P$ ' stand for this content. It's precisely because $P$ is the asserted content of Speaker's utterance that the utterance is objectionable: the utterance involves the literal use of a sentence whose conventional meaning - that he needs four matsis a hopelessly poor way of indicating what Speaker means. One might be skeptical of this claim. One might be inclined to think that Speaker was 
merely intending to assert $P$, not actually asserting it. But keep in mind that Speaker's public display of her intention to assert $P$ is accompanied by Respondent's knowledge that Speaker is intending to assert $P$. The recognition of a communicative intention of this kind suffices for genuine assertion. Why is that? Well, to assert $P$ just is to publically undertake a commitment to retract or defend $P$ if its truth is challenged, and to thereby authorize reliance on (and re-assertion of) $P .^{11}$ And if one's interlocutor recognizes one's intention to assert $P$ by uttering a sentence, then such a commitment has been undertaken. To illustrate, suppose that you recognize my intention to assert that your ride is here waiting for you by uttering the sentence 'You better hurry up!' Now suppose you go to catch your ride and then see that, actually, it isn't here waiting for you. You rightly complain: 'My ride isn't here yet, fool!' But I respond, 'Look I never said it was.' My response is totally inadequate. Its inadequacy is explained by the fact that I failed to live up to a commitment I publically undertook by uttering a certain sentence with a certain intention that you successfully recognized. In short, I made a false assertion that I'm now neither retracting nor defending.

Now, it's widely accepted that irregular uses of 'not' involve an echoic use of the embedded sentence in the initial clause - a use that's intended to be (at least partially) imitative, exhibiting the very infelicity that's meant to be rectified. ${ }^{12}$ We may therefore suppose that, by uttering (10), Respondent is echoing Speaker's use of the problematic sentence, 'He needs /fo:r mæts/', but within the reach of 'not' so as to deny that using the sentence is a perspicuous way of asserting $P$. However, Respondent's use of the problematic sentence, 'He needs /fo:r mæts/', is echoic only if it exhibits the very same infelicity as Speaker's original utterance. This condition requires that Respondent's use of the problematic sentence express $P$ as its asserted content. The reason is that Speaker's utterance is objectionable in virtue of asserting $P$ in a particularly obscure way. Thus the asserted content of the initial clause in (10) is the irregular negation of the very same asserted content expressed by Speaker's problematic utterance, namely, that "he" needs more fats. Consequently, what Respondent would assert if the initial clause of (10) were assigned a descriptive reading instead-that he does

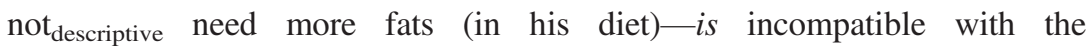
asserted content of the rectification clause. So I conclude that (10) is consistent with (P1).

See Robert Brandom (1994, Ch. 3) and John MacFarlane (2009).

12 Even Carston (1996, pp. 323-324) accepts the thesis that irregular negations involve an "echoic" use of the sentence embedded under 'not', despite her skepticism about so much in Horn $(1985 ; 1989)$ and Burton-Roberts (1989a; 1989b). See also Seizi Iwata (1998) for further discussion of the idea that irregular negations involve echoic use. 


\subsection{Refining $(P 1)$}

(P1) requires an important qualification. Not just any sentence of the form $\lceil$ not- $X ; Y\rceil$ that has an irregular interpretation satisfies $(\mathrm{P} 1)$ as it now stands. For example, consider:

(11) Our radar didn't detect several aircrafts; the word you should use is 'aircraft'.

The initial clause here certainly has an irregular interpretation, and it's clear that a speaker who utters this sentence means to communicate that interpretation. But, if interpreted descriptively, what an utterance of the initial clause would assert is compatible with what an utterance of the rectification clause would assert. What are we to make of this?

The problem, I think, is that we haven't placed any constraints on what can count as an appropriate instance of $\lceil Y\rceil$ in $\lceil$ not- $X ; Y\urcorner$. Elsewhere I've suggested that we take instances of $\lceil Y\rceil$ to be canonical rectifications, but I said less than was required about what a canonical rectification is. At the time, I was unsure about how to properly define the notion to suit my purpose without begging any metaphysical questions. I'm now prepared to offer such a definition.

Let's say that a sentence, $S_{\mathrm{cr}}$, is a canonical rectification with respect to some problematic sentence, $S$, iff two conditions hold. First, $S_{\mathrm{cr}}$ differs from $S$ in one crucial respect: the problematic word or phrase in $S$ has been replaced with a word or phrase that doesn't generate the infelicity one wants to rectify. But for this minimal difference, and the grammatical modifications it might force one to make elsewhere in $S$, the two sentences are the same. Second, $S_{\text {cr }}$ can still be used to achieve roughly the same communicative purpose that the problematic original sentence was used to achieve. The communicative purpose is determined by the contextually salient question under discussion. I'm appealing here to a somewhat technical notion, so let me pause to elaborate.

In his well known article, 'Scorekeeping in a Language Game', David Lewis proposes that we model communication with a scoreboard whose various parameters function to keep track of two related sets of fact: the moves that have already been made in a conversation, and the possible range of felicitous moves that are open to be made. Lewis offers a few concrete suggestions about what these parameters should be: one element of the scoreboard is a set of mutually shared presuppositions; another might be a set of permissions and prohibitions; yet another might be the contextually operative standard of precision. Various theoretical pressures may lead us to expand the conversational scoreboard in any number of ways. For instance, some linguists have posited the "question under discussion" as an additional entry in the conversational scoreboard to represent the more or less local aims of a talk exchange. (See 
Lauri Carlson (1983), Jonathan Ginzburg (1996), and Craige Roberts (2004).) This extension of the familiar scoreboard model allows theorists to explain discourse phenomena that might otherwise seem puzzling, such as focus placement and felicitous topicalization, as well as more familiar Gricean facts. For example, an utterance of an informative sentence - one whose acceptance would reduce the space of open possibilities and thus advance inquiry-may still be irrelevant. Why? Because it fails to address the question under discussion. My definition of 'canonical rectification' should be understood in terms of this very notion: if an utterance of $S_{\mathrm{cr}}$ addresses roughly the same question under discussion to which $S$ was offered as a response, then it satisfies the second condition. Generally reliable intuitions about the relevance of particular moves in a talk exchange can help us to evaluate particular instances of this schematic conditional. For example, reconsider A's exchange with B.

(12) A: Either Wilson or Heath will be the next Prime Minister.

B: I disagree. It's not the case that either Wilson or HEATH will be the Prime Minister; it's either Wilson or THORPE.

Here it's clear that the question under discussion is something like, who will be the next Prime Minister, and an utterance of 'Either Wilson or Thorpe will be the next Prime Minister' is just as much a response to that question as an utterance of 'Wilson or Heath will be the next Prime Minister'. The former is therefore a canonical rectification of the latter, even though 'Thorpe' and 'Heath' are not being used co-referentially. We can thus feel free to use the notion of a canonical rectification without having to worry about begging any important questions.

It's worth mentioning that the second condition of my definition is closely related to some of my remarks in Section 1. The basic idea is that a canonical rectification is a minimally revisionary alternative to the problematic sentence embedded under negation. Thus a canonical rectification of 'Louie C.K. isn't FUNNY' is 'Louie C.K. is HILARIOUS'; a canonical rectification of 'Our radar didn't detect several aircrafts' is 'Our radar detected several aircraft'. But there may well be other sentences that qualify as canonical rectifications; for example, 'Louie C.K. is FREAKIN' HYSTERICAL'.

We should reformulate (P1) to incorporate the notion of a canonical rectification.

(P1*) A sentence of the form $\left\lceil\right.$ not- $X ; Y_{\text {canonical }} 1$ has an irregular interpretation in some context, $c$, only if, in $c$, what's asserted by a literal and sincere utterance of the initial clause on a descriptive reading of 'not', Гnot descriptive $X 1$, is incompatible with what's asserted by a literal and sincere utterance of the rectification clause, $\left\lceil Y_{\text {canonical }} 1\right.$. 
Thus (11) no longer threatens to undermine the first step of my argument. In relation to 'Our radar didn't detect several aircrafts', 'The word you should use is "aircraft"' isn't a canonical rectification.

$\left(\mathrm{P} 1^{*}\right)$ requires that we make one slight modification to our account of relevance-based implicatures. Recall

(9) \#He wasn't able to solve the problem; he didn't solve it.

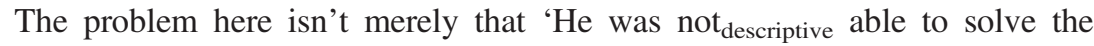
problem' and 'He didn't solve it' are compatible; it's that there isn't any sentence which qualifies as a canonical rectification of the initial clause but which satisfies the consequent of $(\mathrm{P} 1 *)$.

\subsection{Motivating (P2)}

Let me now say a few words about the second step of my argument.

(P2) An instance of 「The piece of alloy isn't $F$, but the statue is 7 has an irregular interpretation in some context.

There are really two separate questions here. First, what evidence is there for thinking that an instance of ГThe piece of alloy isn't $F$, but the statue is 7 has an irregular interpretation? Second, why think the relevant instance of $\ulcorner$ The statue is $F\rceil$ is a canonical rectification of the corresponding instance of $\lceil$ The piece of alloy isn't $F$ ? ? If it weren't a canonical rectification, then we wouldn't be justified in concluding, via $\left(\mathrm{P}^{*}\right)$, that the two sentences are incompatible, and thus the argument would be blocked. In retrospect, neither of these questions was adequately dealt with in my earlier sketch of this argument. Part of the problem was that we didn't have a sufficiently clear idea of what a canonical rectification is.

First thing's first, though: what evidence is there for thinking that an instance of $\lceil$ The piece of alloy isn't $F$, but the statue is 7 has an irregular interpretation in some context? It's useful to focus on a hypothetical conversation. Suppose A is a non-native English speaker who hasn't yet learned how to properly use terms like 'statue' and 'sculpture'. Suppose A and her friend, B, visit an art gallery where they observe an alloy statue. Though she's unable to describe it as such in English, A knows that the artwork in front of her is a statue, and B knows that A knows it's a statue. But, due to her ignorance of English, A says,

(13) The piece of alloy is Romanesque.

Furthermore, suppose that immediately after A speaks, B replies as follows.

(14) Your description is partly right and partly wrong. The piece of ALLOY isn't Romanesque, but the STATUE is. 
At this stage we can ask, regarding B's utterance of the sentence 'The piece of ALLOY isn't Romanesque',

(DIAGNOSTIC) Is the use of 'not', in this context, communicating the speaker's belief that the subject of her speech has a property which is incompatible with the one actually predicated?

Given the sort of context I have in mind, the answer is certainly no, for B does not believe the piece of alloy is Gothic, or Arabesque, or postRomanesque, or pre-Romanesque, or an instance of any other aesthetic style which is incompatible with being Romanesque. Additionally, we may suppose that $\mathrm{B}$ is not a multi-thinger, nor does she have any latent disposition to embrace multi-thingism. In particular, B does not believe that statueconstituting pieces of alloy essentially lack aesthetic properties, such as being Romanesque. In fact, we may suppose that B thinks some artwork-constituting pieces of alloy are Romanesque, for on one occasion, not long before her exchange with A, she said,

(15) I was at the junkyard the other day and I saw a piece of alloy that had to be a work of art. I don't know whether it was a statue, or a sculpture, or a part of some building that's no longer standing, but the form was remarkable! If I had to bet, I would bet that the piece of alloy is Romanesque.

Interestingly, informants report that 'The piece of alloy is Romanesque' occurs felicitously in (15) (Almotahari 2014a), and we can easily imagine a situation in which this very discourse fragment accurately describes the facts. These observations indicate that being an artwork-constituting piece of alloy and being Romanesque are compatible. So B's use of 'not' isn't expressing a belief that "the piece of alloy" has a property incompatible with the one actually predicated. Rather, B's use of 'not' is communicating her belief that there's something objectionable about the linguistic trappings of A's utterance. This explains why B says, about A's description, that it's "partly right and partly wrong". B judges that it's partly right because she takes A to have correctly identified the relevant aesthetic property of the item under discussion. B judges that A's description is partly wrong because it exhibits a certain kind of linguistic infelicity. There's something a little off about describing a piece of alloy as Romanesque when this description isn't qualified in the way that (15) is. Why is that? Why should (13) be infelicitous when uttered by A in the art gallery, but felicitous when 
embedded in (15)? I'll return to this question momentarily. First, let's be clear about what an answer to the question should look like.

It's useful here to compare A and B's exchange with C and D's.

(16) C: Louie C.K. is so funny!

D: Well, you're right and wrong. Louie C.K. isn't FUNNY; he's HILARIOUS!

In each example the speaker says something toward which the respondent expresses both agreement and disagreement. Intuitively, the respondent agrees with the speaker's point, but disagrees with how the point is put. Thus we can specify three constraints that a satisfactory account of the anomalous character of 'The piece of alloy is Romanesque' ought to satisfy. First, it should explain why the sentence is infelicitous when used in isolation, as in (13). Second, it should explain why the sentence is felicitous in (15). Finally, the account should vindicate the intuitive similarity between the significance of 'not' in (14) and D's response in (16). In both cases, the use of 'not' is compatible with agreement about the central point. Onethingers are in a particularly good position to offer an explanation that satisfies all three constraints. I presented just such an account at some length in my earlier work. Let me quickly summarize my story here.

Suppose for the moment that the statue just is the piece of alloy. Now the information one communicates about some object of interest will depend on how one chooses to describe it. If one chooses to describe the object as 'the alloy statue', or simply as 'the statue', then one communicates the belief that it's a work of art. The reason is that it's common knowledge that statues are works of art. So one's interpreter can reasonably conclude on the basis of one's choice of words that one takes the subject of one's speech to be an artwork. However, one might choose to describe the object of interest in different terms. If, for example, one describes it using 'the piece of alloy' instead, then one's speech conversationally implicates that it's not a work of art. The reason is familiar: if one took the object to be a work of art, then one could just as easily have communicated something stronger than what was actually communicated, thus conforming to the conversational maxim Be informative!, without transgressing any of the other maxims that regulate cooperate speech, such as Be relevant! or Be brief!. How could one have done so? One could have used 'the alloy statue' instead. Given that one decided to withhold that additional information, one's interpreter can reasonably infer that one doesn't believe the piece of alloy is a work of art.

In our hypothetical conversation, A utters (13) on its own, without any qualification such as in (15), and fully intends to conform to principles governing cooperative speech. What A said could just as easily have been said 
by using 'The alloy statue is Romanesque'. (Remember, for present purposes, we're assuming that the statue just is the piece of alloy.) Thus A implicates (B can reasonably infer on the basis of Gricean reasoning that $\mathrm{A}$ doesn't believe that) the object is an artwork. But A also indicates that she does believe the object is an artwork, since she goes on to predicate being Romanesque of it. (It's common knowledge that Romanesque artifacts are works of art.) So A represents herself as believing that the subject of her speech is an artwork and as not believing that it's an artwork. Thus an utterance of (13) suffers from pragmatic inconsistency. But this kind of infelicity is perfectly compatible with the literal truth of the sentence. Moore's paradox provides a nice example: 'It's raining, but I don't believe that it is'. Both conjuncts may well be true, and yet by uttering the sentence one would represent oneself as suffering from a conflicted state of mind: believing that it's raining and not believing that it's raining.

In some contexts, however, (13) is felicitous. ${ }^{13}$ Given my explanation of why (13) is anomalous in isolation, it isn't mysterious why it should be felicitous in (15). The pragmatic inconsistency that gives rise to infelicity when (13) is used in isolation is partly due to the implicatum that the speaker doesn't believe the subject of her speech is an artwork. But this problematic implicature is preemptively canceled in (15). The discourse fragment begins with 'I saw a piece of alloy that had to be a work of art', which makes it unreasonable for interpreters to conclude that the speaker doesn't take the subject of her speech to be an artwork. Without this implicature, the speech is pragmatically consistent.

Finally, it should be clear that the story I've been telling vindicates the intuitive similarity between (14) and D's response in (16). Both are cases of implicature denial. The implicature being denied in one case is that the object of interest is not an artwork. The implicature being denied in the other case is that nothing stronger can be said of Louie's sense of humor. In both cases, however, the central point is affirmed. The respondent expresses disagreement with the way the point is put because of an objectionable implicature.

In order to justify (P2), I drew attention to a particular instance of 「The piece of alloy isn't $F$, but the statue is 1 and argued that the DIAGNOSTIC question supports treating it as a case of irregular negation. I deliberately chose to make 'Romanesque' the relevant substituent, for then the argument would exhibit a pleasing irony. It would show that the considerations that were supposed to be most damaging to one-thingism actually support the doctrine. But if readers find this version of the argument unpersuasive, I invite them to consider any number of other substitution instances of the schema in

13 In my earlier presentation of this account I foolishly said that this is a respect in which (13) differs from Moore-paradoxical sentences. This is, of course, false, since Mooreparadoxical sentences can appear felicitously in suppositional contexts (Yalcin 2007). 
(P2). For example, imagine a highly persnickety art dealer who takes umbrage when his goods are talked about in a way that he thinks is objectionably irreverent. One can easily imagine a context in which he utters (17), intending thereby to merely correct his interlocutor's use of language, since 'piece of alloy' is, by the art dealer's lights, too crude a way of referring to art.

(17) The piece of ALLOY isn't suitable for display, but the STATUE is!

Incorporating the speaker's use of negation by adding a negative prefix to 'suitable' would damage the intended communicative effect of his speech, since the speaker may well think - and, in our hypothetical situation, he does think - that the piece of alloy is suitable for display.

(18) \#The piece of ALLOY is unsuitable for display, but the STATUE is suitable!

An utterance of (18) in our imagined context would be an infelicitous way of achieving the desired communicative effect, because the initial clause would express a thought that conflicts with the art dealer's state of mind, thus misrepresenting what he actually believes. The case is relevantly analogous to a familiar example.

(3) \#Louie C.K. is unfunny; he's hilarious.

The initial clause in (3) expresses a thought that conflicts with the speaker's actual belief about the quality of Louie C.K.'s comedy. Given the infelicity of negative prefixing, there's good reason to believe that (17) involves irregular negation. Examples can easily be multiplied, but I think the point has been adequately made, so I won't linger on it. To avoid redundancy, I'll simply formulate the rest of my argument in terms of 'Romanesque', trusting readers to adapt it as necessary to their favorite example.

I began this section by asking two questions. We've talked about the first. Let's focus now on the second. Why think 'The statue is Romanesque' is a canonical rectification of (13)? Well, think about which part of 'The piece of alloy is Romanesque' B finds objectionable in the sort of context we're imagining. Focusing on changing intonation is particularly helpful here, since it draws attention to the element in the initial clause that generates the problem. Reconsider our earlier examples:

(IMPLICATURE Louie C.K. isn't FUNNY; he's HILARIOUS. DENIAL)

(4) Cersei doesn't HATE Tyrion; she LOATHES him. 
Now, when I discuss these matters with undergraduates and uninitiated acquaintances - in particular, when I present to them Kit Fine's (2003; 2006) argument for multi-thingism: the piece of alloy is not Romanesque; the statue is Romanesque; therefore, the piece of alloy and the statue are distinct-I often find myself combining the two premises into one complex construction that exhibits a similar change in intonation: the piece of ALLOY isn't Romanesque (or, alternatively, the PIECE of alloy isn't Romanesque), but the STATUE is. This indicates that the problematic phrase in the initial clause is 'piece of alloy'. Replacing this phrase with 'statue' eliminates what was problematic with the original. This, I take it, is clearly illustrated by B's response to A in (14).

A canonical rectification is a sentence that satisfies two conditions: first, it differs from the corresponding initial clause in only one respect, viz. the problematic word or phrase in the initial clause has been replaced with a word or phrase that doesn't generate the same infelicity; and, second, the sentence can be used to achieve roughly the same communicative purpose. 'The statue is Romanesque' satisfies both conditions in relation to 'The piece of alloy is Romanesque'. I've explained why the first is met; let me now discuss the second.

Consider, again, A's exchange with B. The question under discussion in this context, we may naturally suppose, is what sort of aesthetic style does a certain salient item exhibit. By asserting that the statue is Romanesque, B confirms that A's answer to that question is correct. Intuitively, B's utterance is a relevant conversational move - no less relevant than her response to A in (12). I conclude, therefore, that 'The piece of alloy isn't Romanesque, but the statue is' has an irregular interpretation and is an instance of $\left\lceil\right.$ not- $X ; Y_{\text {canonical }} 7$. Thus $\left(\mathrm{P} 1^{*}\right)$ and $(\mathrm{P} 2)$ jointly yield $(\mathrm{C} 1)$. But once we arrive at $(\mathrm{C} 1)$, the case for one-thingism is all but complete, since the remaining steps are highly attractive. However, as plausible as it may initially seem, (P3) requires an amendment, otherwise it would be susceptible to easy falsification. ${ }^{14}$

\subsection{Refining (P3)}

Suppose Aristotle is the greatest philosopher of antiquity. In a wide range of contexts, then, 'the father of the greatest philosopher of antiquity' and 'his most famous son' would be used to refer to different individuals (Nicomachus and Aristotle, respectively). Even still, in such contexts, the sentences below determine contingent truth-conditions that are incompatible.

14 I'm grateful to Aidan Gray and Matt Teichman for putting pressure on this point. 
(19) The father of the greatest philosopher of antiquity is descended from Adam.

(20) His most famous son is not descended from Adam.

If an assertive utterance of (19) would express a truth in the sort of context we have in mind, then an assertive utterance of (20) would express a falsehood, and vice versa. Therefore, as stated, (P3) is false.

The solution to this problem requires that we draw attention to an important difference between the counterexample and the case to which we want to apply (P3). The relationship between father and son is such that it's metaphysically impossible for the father to be descended from Adam while the son isn't. From our point of view, then, the relevant question is: assuming the piece of alloy and the statue are distinct, is the relationship between the piece of alloy and the statue such that it's metaphysically impossible for the statue to be Romanesque while the piece of alloy isn't? For the counterexample here to be truly analogous to the case we care about, and thus threaten my argument, the answer would have to be yes. But multi-thingers don't think that it is impossible for the statue to be Romanesque while the piece of alloy isn't. In fact, they think that any actual Romanesque statue is Romanesque, while its constituent matter isn't. More generally, the actual divergence between an artifact's aesthetic/functional properties and its constituent matter's aesthetic/functional properties is supposed to motivate multi-thingism. If one thought that such a divergence were metaphysically impossible, what basis would one have for thinking that the artifact is distinct from its constituent matter? ${ }^{15}$ (In fact, the necessity of such convergence would tell in favor of identity, for brute necessities are often thought to be mysterious.) So I think I can respond to the criticism here in one of two ways. Either incorporate an additional clause in (P3) that rules out father-son-type cases, or simply rely on the specific instance of (P3) that involves 'the piece of alloy' and 'the statue' directly, and not bother with the more general principle. The instance of (P3) I ultimately rely on is, I think, plausible enough in its own right.

Suppose we opt for the first strategy. Then there's a relatively conservative way to refine (P3) to avoid easy falsification. Let $R_{F}$ be a relation that holds between $x$ and $y$ iff, assuming $x$ and $y$ are distinct, it's metaphysically and functional properties (e.g., 'Romanesque', 'open', 'shut', etc.) are supposed to be an improvement on the familiar modal and temporal considerations for distinguishing artifacts from constituent matter. One-thingers have strategies for dealing with the modal and temporal considerations that are supposed to be inapplicable to aesthetic and functional considerations. 
impossible for both of them to exist and for one to be $F$ without the other also being $F$. Thus the father of the greatest philosopher of antiquity and his most famous son stand in the $R_{\text {descended-from-Adam }}$ relation, whereas the piece of alloy and the statue don't stand in the $R_{\text {Romanesque }}$ relation. Now we can straightforwardly reformulate (P3) as follows.

$\left(\mathrm{P} 3^{*}\right)$ If what's asserted by a literal and sincere utterance of $\Gamma$ The $F$ is not $_{\text {descriptive }} G 1$ is incompatible with what's asserted by a literal and sincere utterance of $\Gamma$ The $H$ is $G\rceil$, and both of the following conditions are satisfied: (i) the two asserted contents determine contingent truth-conditions and (ii) the $F$ and the $H$ don't stand in the $R_{G}$ relation, then 「The $\left.F\right\rceil$ and $\Gamma$ The $H 1$ are being used in a literal frame of mind to pick out the same object.

We're thus able to arrive at (C2) without the threat of easy falsification.

It's worth briefly returning to my formulation of the central argument in terms of being suitable for display. It seems quite possible that the piece of alloy be unsuitable for display even when the statue is suitable. How's that? Well, a couple of thoughts come to mind. First, one can imagine an artistic trend that revels in irony, very like the fashion trend associated with hipsters. Art in this ironic style is suitable for display partly because the material from which it's made is unsuitable for display. The unsuitability of the piece of alloy, then, contributes to the suitability of the statue. One might not appreciate this sort of artistic trend, or see much of a point to it, but the judgments of its practitioners concerning the relationship between the suitability-for-display of a piece of alloy and the suitability-for-display of the corresponding statue strikes me as coherent. But-and this is the second thought — one needn't imagine a bizarre artistic trend to make the point. It seems perfectly conceivable that the beauty of a statue juxtaposes with the unsuitability-for-display of its constituent alloy in such a way that enhances the quality of the artwork, thus contributing to its suitability for display. ('The artist made this statue using that material?! Remarkable!') These thoughts indicate that the piece of alloy and the statue don't stand in the

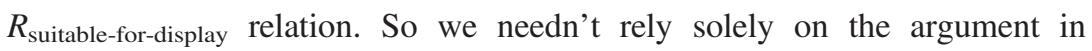
terms of 'Romanesque' to arrive at (C2) via (P3*).

An urgent question now arises. Have I provided multi-thingers with ammunition for a decisive attack against one-thingers? Imagine an alloy statue of the sort I described in the previous paragraph. Then the attack on one-thingism might look something like this:

(i) The statue is suitable for display.

(ii) The piece of alloy is unsuitable for display. 
(iii) Therefore, the statue is distinct from the piece of alloy.

No, one-thingers are equipped with an adequate defense. The predicate 'suitable for display' is implicitly modal, so one-thingers can use their favorite "nonstandard" interpretation of de re modality to render (i) and (ii) compatible with their view. For example, appealing to David Lewis (1983), the one-thinger can interpret (i) and (ii) roughly as follows.

(i*) There's a possible world in which the norms governing artistic displays are followed and in which there's an artifactual counterpart of the statue that's on display.

(ii*) There's a possible world in which the norms governing artistic displays are followed and in which there's a material counterpart of the piece of alloy that's not on display.

Whether $x$ and $y$ are "artifactual counterparts" is a matter of whether $x$ and $y$ qualitatively resemble each other along dimensions of similarity appropriate for comparing artifacts (similarity with respect to representational, functional, and aesthetic properties). Whether $x$ and $y$ are "material counterparts" is a matter of whether $x$ and $y$ qualitatively resemble each other along dimensions of similarity appropriate for comparing material objects (similarity with respect to physical properties). What follows from (i*) and (ii*) is that the relevant counterparts are distinct. In $\left(i^{*}\right)$ and (ii*), 'the statue' and 'the piece of alloy' are intersubstitutable salva veritate. For further discussion and defense of this strategy in response to modal/temporal challenges to one-thingism, see Almotahari (2014a).

\subsection{False advertising?}

At this point, one might complain that I'm guilty of false advertising. I promised to offer a local basis for choosing one-thingism, not simply the more specific thesis that the statue is identical with the piece of alloy. One-thingism entails the more specific thesis, but it's actually a much more general doctrine about the nature of material objects. It says that a material object is identical with its constituent matter. This more general doctrine doesn't logically follow from anything I've said so far.

True enough. But consider the role that the alloy statue is supposed to play in the ongoing struggle between one-thingers and multi-thingers. It's supposed to be a paradigm of non-identity between a material thing and its constituent matter. Multi-thingers present the case as if it were a clear counterexample to one-thingism. That the piece of alloy is distinct from the statue is precisely what one would expect, then, if one-thingism were false 
and multi-thingism true. Given the dialectical role that the case plays, it would be strange indeed if multi-thingism were true and yet the relationship between alloy and statue were identity. So I want to recommend an additional consideration.

(P4) If multi-thingism is true, then the piece of alloy isn't the statue.

Thus, given (C3), it follows rather straightforwardly that one-thingism is true. This concludes my presentation and defense of the central argument.

\section{From metaphysics to metametaphysics}

I want to conclude with a lingering puzzle and a bold (though certainly not original) claim about its solution.

My reason for choosing one-thingism crucially turns on some linguistic considerations. Multi-thingers, too, rely on claims about natural language when arguing for their view. For example, Kit Fine (2003; 2006) draws our attention to a certain range of predicates.

[...] the predicates in question have felicitous application to the one subject term but not to the other. Thus we can say that the door is open or shut but we cannot very well say that the plastic from which it is made is open or shut; [and the statue can be Romanesque but we cannot say that the underlying piece of alloy is]. As I mentioned in the original paper [2003, p. 207], these various sorts give rise to their own "sphere of discourse"; and predicates within one sphere will often not have felicitous application to objects belonging to other spheres (Fine 2006, pp. 1069-1070).

But why should linguistic considerations resolve controversies about the metaphysics of material objects? To put things in perspective, and raise the metametaphysical puzzle I have in mind a bit more forcefully, an analogy may help.

Imagine a critic who argues as follows. "No one would be foolish enough to presume that the study of natural language can resolve substantive controversies about the physics of macroscopic material objects. Why should metaphysics be any different in this respect?" I'm imagining that the critic understands my central argument, so she's not asking for further clarification about any particular step, nor is she rejecting a specific premise or inference. She's expressing a more abstract methodological puzzlement.

The puzzlement I'm voicing can be formulated in a slightly different way, which draws attention to its distinguished history. Kant famously asked how metaphysics is possible. If either Fine's argument or mine is successful, then either he or I will have demonstrated the possibility of proving metaphysical conclusions from considerations about natural language, since either he or I will have actually done so. But, one might 
worry, even if we acknowledge this possibility, we will not have come any closer to understanding how it's possible.

I believe the puzzle rests on a widely shared assumption that the metaphysics of ordinary objects is a factual enterprise primarily concerned with the way non-linguistic elements of the world are. The key to its resolution, I believe, is acknowledging that the metaphysics of ordinary objects (or, at the very least, that part of it to which I direct my attention) is a verbal dispute that happens to be cloaked in the material mode of speech. For if we abandon the shared assumption and think instead that, at bottom, the disagreement is a kind of verbal dispute, then it's no longer puzzling why linguistic observations should resolve the matter. Verbal disputes are just the sort of disagreement that one should expect to be resolved (or, at the very least, advanced) by linguistic considerations. But properly developing this idea would require another paper. So I won't pursue it any further here. ${ }^{16}$

\section{References}

Almotahari, M. 2014a. 'Metalinguistic Negation and Metaphysical Affirmation'. Philosophical Studies 167: 497-517.

2014b. 'The Identity of a Material Thing and its Matter'. Philosophical Quarterly 64: 387-406.

Bennett, K. 2009. 'Composition, Colocation, and Metaontology'. In D. Chalmers, D. Manley, and R. Wasserman, eds., Metametaphysics: New Essays on the Foundations of Ontology. Oxford: Oxford University Press. Page references to online version: https://courses.cit.cornell.edu/ kb383/CCMsept2007.pdf

Brandom, R. 1994. Making It Explicit. Cambridge, MA: Harvard University Press.

Burton-Roberts, N. 1989a. ‘On Horn's Dilemma: Presupposition and Negation'. Journal of Linguistics 25: 95-125.

1989b. The Limits to Debate. Cambridge, UK: Cambridge University Press.

Carlson, L. 1983. Dialogue Games: An Approach to Discourse Analysis. Dordrecht: Reidel.

Carston, Robyn. 1996. 'Metalinguistic Negation and Echoic Use'. Journal of Pragmatics 25: 309-330. paper. I'm grateful for their helpful feedback. I'm also grateful for the editorial advice and criticism of an anonymous referee. Any remaining errors are my fault. As usual, special thanks to Aidan for reading multiple drafts and patiently enduring many hours of conversation. He must not have had anything better to do. 
Cohen, A. 2006. 'How to Deny a Presupposition'. In K. Turner and von Heusinger K., eds., Where Semantics Meets Pragmatics. Amsterdam: Elsevier. Page references to online version: http://www.bgu.ac.il/ $\sim$ arikc/denial.pdf

Davis, Wayne. 2011. "Metalinguistic" Negations, Denial, and Idioms'. Journal of Pragmatics 43: 2548-2577.

Fine, K. 2003. 'The Non-Identity of a Material Thing and its Matter'. Mind 112: 195-234.

2006. 'Arguing for Non-Identity: A Response to King and Frances'. Mind 115: 1059-1082.

Geurts, B. 1998. 'The Mechanisms of Denial'. Language 74: 274-307.

Ginzburg, J. 1996. 'The Semantics of Interrogatives'. In S. Lappin, ed., The Handbook of Contemporary Semantic Theory. Malden, MA: Wiley-Blackwell.

Grice, H. P. 1989. Studies in the Ways of Words. Cambridge, MA: Harvard University Press.

Higginbotham, J. 1985. 'On Semantics'. Linguistic Inquiry 16: 547-593.

Horn, L. 1985. 'Metalinguistic Negation and Pragmatic Ambiguity'. Language 61: 121-174.

1989. A Natural History of Negation. Stanford: CSLI.

Iwata, S. 1998. 'Some Extensions of the Echoic Analysis of Metalinguistic Negation'. Lingua 105: 49-65.

Lewis, D. 1983. Philosophical Papers, Volume I. Oxford: Oxford University Press.

MacFarlane, J. 2009. 'What is Assertion?'. In J. Brown and H. Cappelen, eds., Assertion. Oxford: Oxford University Press.

2014. Assessment Sensitivity: Relative Truth and its Applications. Oxford: Oxford University Press.

Pitts, Alyson. 2011. 'Exploring a "Pragmatic Ambiguity" of Negation'. Language 87: 346-368.

Roberts, C. 2004. 'Context in Dynamic Interpretation'. The Handbook of Pragmatics. Malden, MA: Wiley-Blackwell.

Rogers, A. 2009. 'How Might Metalinguistic Negation Work?' http:// www.armadilloresearch.org/wp-content/uploads/2009/01/Metalinguistic Negation09.pdf. Unpublished manuscript.

Yalcin, S. 2007. 'Epistemic Modals'. Mind 116: 983-1026. 